\title{
Assessment and Prediction for China's Regional Agricultural Sustainability
}

\author{
Yu Zhao, Qiyang Xie, Yu Zhang* \\ School of Economics and Management, East China University of Technology, Nanchang 330013, China
}

\begin{abstract}
This paper proposes a sustainable agricultural development index (SADI) and a hybrid grey model for measuring the changes in agricultural sustainability over time. Firstly, a comprehensive indicator system for co-evaluating the level of agricultural economy, resource, environment, ecology, technology and rural society is presented based on a holistic understanding of agricultural sustainability. Then, the entropy-based TOPSIS model, grey prediction theory and genetic algorithm are combined to build a synthesis method for evaluating and predicting agricultural sustainability and detecting its regional heterogeneity. Furthermore, an empirical study at a provincial scale is conducted by collecting panel data from 2003 to 2017. The result shows that regional agricultural sustainability in China will continue to improve, with different rates in the different provinces from 2020 to 2030 . And the regional heterogeneity of agricultural sustainability will increase significantly.
\end{abstract}

\section{Introduction}

China is the most populous country, so food security is critical. In order to meet the growing demand, agricultural production is facing tremendous pressure. Under the background, the widespread use of chemical fertilizers and pesticides has promoted the mechanization of agriculture and significantly improved agricultural production. The loss of farmland caused by rapid industrialization and urbanization is worrisome. In 2013, the Minster of Land and Resource of the People's Republic of China said that plants would not grow on about 3.33 million hectares of land because of the severe pollution. With the rapid development of rural economic, the environmental and fossil-fuel energy problems in China have caused a profound reflection on China's agricultural development policies. To ensure food security and agroecological security, the fundamental strategy of China's current and future agricultural development is to take the road of sustainable agricultural development. Without ecological destabilization, sustainably feeding China's growing population is a huge challenge.

Measuring agricultural sustainability has great significance, thus government must set goals and track progress. From the perspective of regional coordinated development, agricultural sustainability evaluation should consider the regional heterogeneity, and forecast the trends of the regional agricultural sustainability and its regional heterogeneity. And crucially, relevant reasons for regional heterogeneity must be found. Assessment tools of agricultural sustainability, such as development indicators and various comprehensive indicators, have been widely used. However, research on evaluation models of agricultural sustainability involving the interaction and relationship among the subsystems are still in their primary stages. The purpose of the contribution is to assess and predict the sustainability of China's provincial agriculture and enable people to scrutiny regional changes caused by existing differences in agricultural activities at this level in terms of extension, relevance and policy.

\section{Literature Review}

Economic theory to measure the sustainable economic growth model was developed more than half a century ago. It was not until 1987 that the concept of sustainable development, formally put forward by the United Nations World Commission on Environment and Development, received great attention from governments and media around the world[1]. Establishing of the indicator system is the basis of sustainable development evaluation, and a scientific indicator system is the basic guarantee to support the implementation of sustainable development. The Commission on Sustainable Development established a sustainable development evaluation system with 134 indicators in 1995. Subsequently, many countries actively explored sustainable development on global, regional and national scales. Lots of homologous indicator systems were constructed and applied[2-3]. Mili suggested that an evaluation system should fully reflect the quantity and quality of agricultural development from the following dimensions: food security, ecological stability, rural economic development and intra-regional balance[4]. Cui claimed that sustainable development of regional

* Corresponding author: 1765674144@qq.com 
agriculture had five factors: agricultural economy, rural society, agricultural resources and environment, agricultural production, and agricultural technology[5].

Most of the previous studies on sustainable agricultural development only focused on the aspects of economic, social, and environmental when subsystems were establishing, while they usually ignored the potential impact of agricultural resource, agroecology and agricultural technology. However, technical factors as well as the agricultural resource and agroecology play vital roles in sustainable agricultural development because they reflect the degree of social progress. Therefore, in order to more accurately reflect sustainable development of agricultural regional, the paper proposed an evaluation system including six factors. Their interrelationships are shown in Figure 1.

There are many different approaches and tools for assessing agricultural sustainability. At present, the methods widely used are sociological and economic methods, including national economic accounting[6], human development index[7], ecological methods, including synthetic index of energy sustainable development[8], material streaming, ecological footprint, TOPSIS[9]. Based on different theories, some scholars built evaluation systems and adopted entropy weight method, analytic hierarchy process or factor analysis[10] to assign weights and evaluate each index. As a whole, TOPSIS and the improved entropy weight method are often employed to select suitable variables and optimize model parameters.

Even though the above methods have successfully evaluated sustainable development of agricultural, it can't help us to accurately judge the changing trend of agricultural sustainable development. Therefore, we combined the entropy-based TOPSIS model, grey prediction theory to build a synthesis method for evaluating and predicting agricultural sustainability. The highlights of this paper may be as follows:
(1) Our measure of agricultural sustainability is the extended form of agricultural development degree and agricultural coordination degree. In our opinion, agricultural sustainability is a comprehensive concept, development and coordination of agricultural subsystems both should be considered.

(2) Based on more complete indicator system, a more objective evaluation method, entropy-based TOPSIS model, is used to ensure the evolving sustainable development process is fully revealed.

(3) The hybrid grey model constructed based on genetic algorithm is more accurate than $\operatorname{EGM}(1,1)$ model and Verhulst model. The trend of regional agricultural sustainability can be captured accurately by our hybrid grey model.

\section{The Indicator System}

The indicator system of the agricultural sustainable development evaluation model should comprehensively cover the main interrelated factors such as social, economic, technological, ecological and environmental. The determination of subsystems' factors depends on comprehensive reference of the sustainable development from international organizations and the government of China. China's National Plan for Sustainable Agricultural Development (2015-2030) defines the key aspects that should be focused on currently. For a complex system, the measurement should not only focus on the changes of each component separately, but also on the close interactions and correlations. Figure 1 shows the final indicator system framework for sustainable agricultural development. It shows the relationships of each subsystem. At the bottom of the model, subsystems are measured by representative indicators.

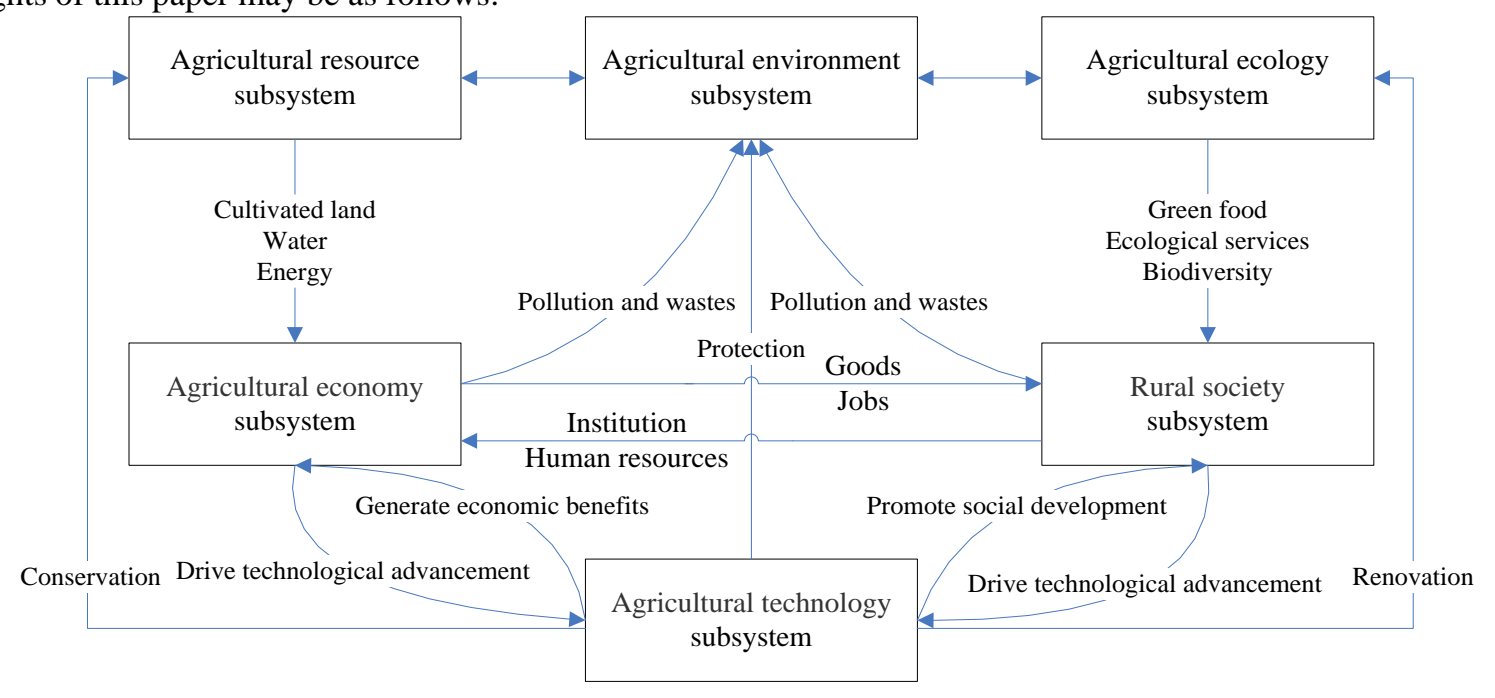

Figure 1. The framework of the indicator system of sustainable agricultural development

Based on the framework, we then referred to the China fiscal Yearbook, the China Energy Yearbook, the China rural statistical yearbook, the China Water Resources Statistical Yearbook and the China Annual
Statistical Report of Green Food to select appropriate indicators for the measurement of each subsystem and to confirm the availability of provincial data. Then the selected indicators were further selected by comparing 
the correlation coefficients and significance levels between any two indicators. 26 agricultural sustainability indicators were selected in this study: five resource-related, three environmental, four agroecological, six economic, four social and four technological indicators. Table 1 shows the final indicator system.

Table 1. The indicator system of sustainable development for agriculture in China

\begin{tabular}{|c|c|c|c|}
\hline Subsystem & Indicator & Units & Types \\
\hline \multirow{5}{*}{$\begin{array}{l}\text { Agricultural } \\
\text { resource }\end{array}$} & Per-capita arable land area & ha & benefit index \\
\hline & The multiple cropping index & - & cost index \\
\hline & Water consumption per unit agricultural output value & ton/CNY & cost index \\
\hline & The proportion of water-saving irrigation area & $\%$ & benefit index \\
\hline & Energy consumption per unit agricultural output value & tce/ CNY & cost index \\
\hline \multirow{3}{*}{$\begin{array}{l}\text { Agricultural } \\
\text { environment }\end{array}$} & The amount of fertilizer used per hectare cultivated land & $\mathrm{kg} / \mathrm{ha}$ & cost index \\
\hline & The amount of pesticide used per hectare cultivated land & $\mathrm{kg} / \mathrm{ha}$ & cost index \\
\hline & The amount of agricultural film used per hectare of cultivated land & $\mathrm{kg} / \mathrm{ha}$ & cost index \\
\hline \multirow{4}{*}{ Agroecology } & The percentage of forest area in the territory of the region & $\%$ & benefit index \\
\hline & The percentage of wetland area in the territory of the region & $\%$ & benefit index \\
\hline & The percentage of nature reserves area in the territory of the region & $\%$ & benefit index \\
\hline & The number of certified quantity of green food & per ha & benefit index \\
\hline \multirow{6}{*}{$\begin{array}{l}\text { Agricultural } \\
\text { economy }\end{array}$} & Per capita net income of farmers & CNY & benefit index \\
\hline & Agricultural labor productivity & CNY & benefit index \\
\hline & Ratio of agricultural added value to intermediate consumption & - & benefit index \\
\hline & The price index ratio of agricultural products to industrial products & $\longrightarrow$ & benefit index \\
\hline & The income ratio of urban and rural residents & $\longrightarrow$ & cost index \\
\hline & Rural Engel coefficient & $\longrightarrow$ & cost index \\
\hline \multirow{4}{*}{$\begin{array}{l}\text { Rural } \\
\text { society }\end{array}$} & The number of old-age care institutions in rural & per 1,000 people & benefit index \\
\hline & The number of clinics in rural & per 1,000 people & benefit index \\
\hline & The number of teachers in rural primary and secondary school & per 1,000 people & benefit index \\
\hline & Per capita subsistence allowance for the poor & CNY & benefit index \\
\hline \multirow{4}{*}{$\begin{array}{l}\text { Agricultural } \\
\text { technology }\end{array}$} & Per capita public expenditure on technology & $\%$ & benefit index \\
\hline & The percentage of the planting area of high quality seeds & $\%$ & benefit index \\
\hline & The percentage of agricultural technicians & $\%$ & benefit index \\
\hline & Per capita number of new crop variety right applications & per 1,000 people & benefit index \\
\hline
\end{tabular}

\subsection{Entropy-based TOPSIS Model}

According to Liu[11], the steps of entropy-based TOPSIS model are summarized as follows.

Step 1: Construct normalized decision matrix.

Suppose there are $m$ evaluating objects and $n$ indicators. Then, we can obtain the decision matrix D. Since the evaluation criteria for data have no uniform dimension, we need to normalize the data. by using Eq.1.
Step 2: Construct the weighted normalized decision matrix.

The normalized weight matrix $\mathrm{S}=\left(s_{i j}\right)_{m \times n}$ can be constructed by multiplying $\mathrm{w}_{\mathrm{j}}$ with $\mathrm{v}_{\mathrm{ij}}, \mathrm{s}_{\mathrm{ij}}=\mathrm{w}_{\mathrm{j}} \mathrm{v}_{\mathrm{ij}}$.

Step 3: Determine the ideal and negative-ideal solution, respectively.

Combining the weight matrix, the positive/negative ideal value $E_{j}^{+} / E_{j}^{-}$can be calculated by Eq.(2) or Eq.(3). 


$$
\begin{aligned}
& E_{j}^{+}=\left\{\begin{array}{l}
\max _{0 \leq i \leq m}\left(s_{i j}\right) \text { benefit criteria } \\
\min _{n<i<m}\left(s_{i j}\right) \text { cost criteria }
\end{array}\right. \\
& E_{j}^{-}=\left\{\begin{array}{l}
\min _{0 \leq i \leq m}\left(s_{i j}\right) \text { benefit criteria } \\
\max _{n<i<m}\left(s_{i j}\right) \quad \text { cost criteria }
\end{array}\right.
\end{aligned}
$$

Step 4: Calculate the separation measures using Euclidean distance.

The Euclidean distances, between $\mathrm{V}_{\mathrm{i}}$ and positive ideal point $E_{j}^{+}$, and between $\mathrm{V}_{\mathrm{i}}$ and negative ideal point $E_{j}^{-}$are calculated, respectively, as

$$
\left\{\begin{array}{l}
S_{i}^{+}=\sqrt{\sum_{j=1}^{n}\left(v_{i j}-E_{j}^{+}\right)^{2}} \\
S_{i}^{-}=\sqrt{\sum_{j=1}^{n}\left(v_{i j}-E_{j}^{-}\right)^{2}}
\end{array} i=1,2, \ldots, m .\right.
$$

Step 5: Calculate the closeness coefficient $\mathrm{C}_{\mathrm{i}}$.

$$
C_{i}=\frac{s_{i}^{-}}{S_{i}^{+}+s_{i}^{-}}
$$

A closeness coefficient is defined to determine the rank order of all municipalities and provinces. The higher the closeness coefficient, the better the rank. Closeness coefficients of agricultural resource, agricultural environment, agroecology, agricultural economy, rural society and agricultural technology are recorded as $\mathrm{C}=\left[C_{i, 1}, C_{i, 2}, C_{i, 3}, C_{i, 4}, C_{i, 5}, C_{i, 6}\right]$.
We can get agricultural development degree $\mathrm{Z}$ using entropy model on closeness coefficient matrix $C$. The agricultural coordination degree can also be calculated by the matrix $\mathrm{C}$. The degree of coordination measures the average difference between any subsystems and treats the differences as a discordant phenomenon. The coordination degree are calculated as,

$$
\gamma_{i}=1-\frac{\sum_{k, l}^{m}\left|c_{i, k}-c_{i, l}\right|}{m \times(m-1) / 2}
$$

The value 1 represents the state of absolute coordination. Hence, the coordination degree is the difference between one and the extent of discordance. Where $\gamma$ represents the coordination degree, $C_{i, k}$ and $C_{i, 1}$ represent any two different subsystems of region $\mathrm{i}$, respectively, and $\mathrm{k}, \mathrm{l} \in[1, \mathrm{~m}], \mathrm{k} \neq 1, \mathrm{~m}$ is the number of subsystems. The sustainable agricultural development index (SADI) can be defined as the square root of the product of agricultural development degree and coordination degree[12], that is:

$$
S A D I=\sqrt{\gamma \times Z}
$$

\subsection{Hybrid Grey Model}

Grey system theory is a methodology that focuses on the study of small data and poor information. In order to forecast the agricultural sustainable development in China, we consider the following even grey model $(\operatorname{EGM}(1,1))$ :

$$
\hat{x}_{E G M}^{(1)}(t)=\left(x^{(0)}(1)-\frac{b}{a}\right) e^{-a(t-1)}+\frac{b}{a}
$$

Where

$X^{(0)}=\left(x^{(0)}(1), x^{(0)}(2), \ldots, x^{(0)}(n)\right), x^{(0)}(k) \geq 0$, $\mathrm{X}(1)$ is the 1 -AGO sequence of $\mathrm{X}(0)$, The parameter a is called development index reflecting the trend of sequences $\mathrm{x}$, and $\mathrm{b}$ is called grey actuating quantity.

The solution of the EGM $(1,1)$ model is an exponential curve, so its predicted geometry is a smoother curve, which can only describe the monotonous change. $\operatorname{EGM}(1,1)$ model is unperfect,

$$
\hat{x}_{\text {Verhulst }}^{(1)}(t)=\frac{c x^{(0)}(1)}{d x^{(0)}(1)+\left[c-d x^{(0)}(1)\right] e^{c t}}
$$

In order to make full use of the advantages of EGM $(1,1)$ and Verhulst model, we consider the following hybrid model:

$$
\hat{x}_{\text {hybrid }}^{(0)}(t)=\lambda \hat{x}_{E G M}^{(0)}(t)+(1-\lambda) \hat{x}_{\text {Verhulst }}^{(1)}(t)
$$

The values of parameters $a, b, c, d$ and $\lambda$ can be obtained by solving the minimum values of the following functions.

$$
S S R=\sum\left(x(t)-\hat{x}_{\text {hybrid }}^{(0)}(t)\right)^{2}
$$

where $x(t)$ is the original sequence, $\hat{\mathrm{x}}_{\text {hybrid }}^{(0)}(\mathrm{t})$ is the predicted sequence obtained by employing hybrid model, and SSR are residual sum of squares. The relative error, when the increase of sequences $\mathrm{x}$ is according to the curve with shape of alphabet $S$ or the increment of sequences $\mathrm{x}$ is in the saturation stage, the forecasting error by $\operatorname{EGM}(1,1)$ model will be bigger. Pointing to this feature, the grey Verhulst model is established to forecast the SADI. We consider the following Verhulst model:

mean square error ratio and small error probability proposed by Liu are used to test the applicability of the gray model[13]. The parameters of Eq. (11) are solved by genetic algorithm optimization function in Matlab GA toolbox.

\section{Results}

\subsection{Assessment of Regional Agricultural Sustainability}

We collect the panel data from 2003 to 2017 for all the provincial regions in China, including four municipalities and twenty seven provinces. In other 
words, there are 465 observations in the quantitative analysis. The weights of indicators and subsystems are obtained using entropy weight method. Based on these weights, we calculate the closeness coefficient and SADI for each region in each year.

The closeness coefficients C, agricultural development degree $\mathrm{Z}$, agricultural coordination degree $\gamma$ and SADI for each region in each year are obtained using Eq. (1)-(7). Then we calculate the average value of the subsystems' closeness coefficients of each region from 2003 to 2017 for the analysis of spatial variation of sustainable agricultural development in Mainland China. The average value of closeness coefficients of all subsystem, agricultural development degree, agricultural coordination degree and SADI are shown in Table 2.

As shown in table 2, high-scoring regions of agricultural resources mainly include the main grain producing areas and the western provinces with better development of water-saving agriculture, such as Shaanxi and Gansu. High-scoring regions of agricultural environmental are mainly located in the country's breadbasket region and Western China. Because of the more serious agricultural pollution in Eastern China, the provincial difference of this indicator is large. High-scoring regions of agroecology are located in the developed regions such as Beijing, Tianjin, the Yangtze River Delta and Qinghai Tibet Plateau. High-scoring regions of agricultural economy are located in Eastern China. High-scoring regions of rural society are located in Beijing, Shanghai, Tianjin and Chongqing. High-scoring regions of agricultural technology are Beijing, Shanghai and Tianjin. From the perspective of coordination, development and sustainability, the scores of Eastern Coastal China are higher than those in Central and Western China.

Table 2. The value of evaluation results

\begin{tabular}{|c|c|c|c|c|c|c|c|c|c|}
\hline & $C_{i, 1}$ & $C_{i, 2}$ & $C_{i, 3}$ & $C_{i, 4}$ & $C_{i, 5}$ & $C_{i, 6}$ & $\gamma$ & Z & SADI \\
\hline Beijing & 0.571 & 0.554 & 0.305 & 0.456 & 0.383 & 0.397 & 0.810 & 0.441 & 0.595 \\
\hline Tianjin & 0.579 & 0.723 & 0.194 & 0.412 & 0.280 & 0.204 & 0.736 & 0.391 & 0.535 \\
\hline Hebei & 0.600 & 0.812 & 0.078 & 0.341 & 0.224 & 0.061 & 0.638 & 0.342 & 0.466 \\
\hline Shanxi & 0.569 & 0.865 & 0.061 & 0.251 & 0.245 & 0.048 & 0.624 & 0.329 & 0.453 \\
\hline Neimenggu & 0.727 & 0.914 & 0.096 & 0.334 & 0.242 & 0.048 & 0.579 & 0.381 & 0.469 \\
\hline Liaoning & 0.615 & 0.691 & 0.150 & 0.381 & 0.228 & 0.051 & 0.683 & 0.343 & 0.484 \\
\hline Jilin & 0.663 & 0.842 & 0.135 & 0.378 & 0.216 & 0.051 & 0.620 & 0.369 & 0.478 \\
\hline Heilongiiang & 0.752 & 0.929 & 0.158 & 0.367 & 0.178 & 0.038 & 0.572 & 0.391 & 0.472 \\
\hline Shanghai & 0.529 & 0.534 & 0.464 & 0.501 & 0.358 & 0.189 & 0.833 & 0.425 & 0.593 \\
\hline Jiangsu & 0.574 & 0.780 & 0.204 & 0.470 & 0.198 & 0.064 & 0.661 & 0.372 & 0.495 \\
\hline Zhejiang & 0.564 & 0.624 & 0.218 & 0.466 & 0.261 & 0.074 & 0.725 & 0.359 & 0.509 \\
\hline Anhui & 0.576 & 0.817 & 0.104 & 0.280 & 0.203 & 0.104 & 0.662 & 0.337 & 0.472 \\
\hline Fujian & 0.562 & 0.590 & 0.198 & 0.376 & 0.211 & 0.051 & 0.730 & 0.323 & 0.485 \\
\hline Jiangxi & 0.542 & 0.795 & 0.168 & 0.306 & 0.242 & 0.026 & 0.665 & 0.336 & 0.472 \\
\hline Shandong & 0.593 & 0.673 & 0.137 & 0.349 & 0.196 & 0.091 & 0.704 & 0.331 & 0.482 \\
\hline Henan & 0.580 & 0.812 & 0.060 & 0.288 & 0.206 & 0.029 & 0.630 & 0.318 & 0.447 \\
\hline Hubei & 0.563 & 0.757 & 0.127 & 0.361 & 0.221 & 0.045 & 0.666 & 0.336 & 0.472 \\
\hline Hunan & 0.531 & 0.810 & 0.138 & 0.332 & 0.219 & 0.033 & 0.655 & 0.334 & 0.467 \\
\hline Guangdong & 0.537 & 0.683 & 0.152 & 0.350 & 0.207 & 0.126 & 0.727 & 0.334 & 0.493 \\
\hline Guangxi & 0.581 & 0.824 & 0.123 & 0.272 & 0.172 & 0.023 & 0.635 & 0.321 & 0.452 \\
\hline Hainan & 0.583 & 0.470 & 0.144 & 0.347 & 0.193 & 0.144 & 0.766 & 0.307 & 0.485 \\
\hline Chongqing & 0.558 & 0.883 & 0.115 & 0.343 & 0.296 & 0.047 & 0.626 & 0.362 & 0.476 \\
\hline Sichuan & 0.588 & 0.877 & 0.149 & 0.317 & 0.209 & 0.045 & 0.628 & 0.353 & 0.471 \\
\hline Guizhou & 0.567 & 0.940 & 0.079 & 0.215 & 0.202 & 0.046 & 0.603 & 0.330 & 0.446 \\
\hline Yunnan & 0.581 & 0.854 & 0.123 & 0.240 & 0.179 & 0.036 & 0.632 & 0.324 & 0.452 \\
\hline Tibet & 0.456 & 0.945 & 0.219 & 0.216 & 0.284 & 0.075 & 0.653 & 0.356 & 0.482 \\
\hline Shaanxi & 0.618 & 0.834 & 0.095 & 0.262 & 0.209 & 0.048 & 0.630 & 0.333 & 0.458 \\
\hline Gansu & 0.612 & 0.712 & 0.131 & 0.207 & 0.220 & 0.107 & 0.697 & 0.323 & 0.474 \\
\hline Qinghai & 0.543 & 0.937 & 0.213 & 0.247 & 0.237 & 0.083 & 0.646 & 0.367 & 0.486 \\
\hline Ningxia & 0.556 & 0.893 & 0.090 & 0.274 & 0.196 & 0.099 & 0.635 & 0.341 & 0.464 \\
\hline Xinjiang & 0.533 & 0.703 & 0.088 & 0.320 & 0.240 & 0.037 & 0.684 & 0.310 & 0.460 \\
\hline
\end{tabular}




\subsection{Regional Agricultural Sustainability from 2020 to 2030}

We use formulas (8)-(11) to predict agricultural sustainability from 2020 to 2030 . The mixed grey model parameters and the predicted values of SADI obtained by genetic algorithm are shown in Table 3 . The results show that lower SSR, Q, DR and higher Prob indicate that the predicted value of grey model is closer to the actual value. After comparing the prediction effect of three grey models in 31 provinces, it is found that the prediction accuracy of mixed grey model is higher than that of $\operatorname{EGM}(1,1)$ model and Verhulst model.

The results show that the gap in agricultural sustainability among Eastern, Central and Western China will further grow due to the differences in the basis and development speed of agriculture. The coefficients of variation of SADI in China is 0.103 by 2020, which will be 0.124 by 2025 and 0.153 by 2030 . The range of SADI in China is 0.229 by 2020 , which will be 0.313 by 2025 and 0.392 by 2030 . In the next decade, the agricultural sustainability of the breadbasket provinces will be improved. The breadbasket regions with SADI scores below the national median by 2030 are only Inner Mongolia, Jilin, Liaoning, and Sichuan. The provinces with high-quality agricultural development are mainly located in the developed regions. In addition, the speed of sustainable agricultural development in Beijing, Liaoning, Jiangsu and Zhejiang will continue to decline, and that in Anhui, Henan, Hubei and Hunan will rise further.

From 2020 to 2030, the gap in agricultural sustainability among Eastern, Central and Western China will be widened gradually. With the help of Grain Support Projects, the gap in SADI between Central China and Western China will be greater. With the help of Grain Support Projects, agriculture in Central China shows high-speed balanced development from 2020 to 2030. Agriculture in Western China will still show low-speed unbalanced development under the policy of restricting the development of key ecological functional areas. Therefore, it is necessary to discuss the feasibility of economic compensation for the limitations of certain land uses in Western China.

Table 3. Parameters obtained by genetic algorithm and predicted values of SADI

\begin{tabular}{|c|c|c|c|c|c|c|c|c|c|c|c|}
\hline \multirow{2}{*}{ Region } & \multicolumn{5}{|c|}{ hybrid grey model } & \multirow{2}{*}{2020} & \multirow{2}{*}{2025} & \multirow{2}{*}{2030} & \multirow{2}{*}{$\begin{array}{c}\text { 2015-20 } \\
\text { Tempo }\end{array}$} & \multirow{2}{*}{$\begin{array}{c}\text { 2020-25 } \\
\text { Tempo }\end{array}$} & \multirow{2}{*}{$\begin{array}{c}2025-30 \\
\text { Tempo }\end{array}$} \\
\hline & a & $\mathrm{b}$ & $\mathrm{c}$ & $\mathrm{d}$ & $\lambda$ & & & & & & \\
\hline Beijing & -0.010 & 0.383 & -0.264 & -0.312 & 0.408 & 0.682 & 0.695 & 0.706 & $0.60 \%$ & $0.38 \%$ & $0.32 \%$ \\
\hline Tianjin & -0.045 & 0.450 & -0.359 & -0.730 & 0.315 & 0.649 & 0.728 & 0.827 & $2.15 \%$ & $2.43 \%$ & $2.72 \%$ \\
\hline Hebei & -0.022 & 0.424 & 0.295 & 0.647 & 0.784 & 0.507 & 0.553 & 0.614 & $0.95 \%$ & $1.81 \%$ & $2.21 \%$ \\
\hline Shanxi & -0.015 & 0.419 & -0.292 & -0.672 & 0.547 & 0.494 & 0.518 & 0.543 & $0.89 \%$ & $0.97 \%$ & $0.97 \%$ \\
\hline Neimenggu & -0.010 & 0.436 & -0.428 & -0.952 & 0.892 & 0.514 & 0.538 & 0.564 & $0.94 \%$ & $0.93 \%$ & $0.97 \%$ \\
\hline Liaoning & -0.029 & 0.281 & -0.155 & -0.293 & 0.067 & 0.519 & 0.527 & 0.535 & $0.47 \%$ & $0.31 \%$ & $0.30 \%$ \\
\hline Jilin & -0.037 & 0.442 & 0.155 & 0.341 & 0.219 & 0.519 & 0.536 & 0.545 & $0.84 \%$ & $0.66 \%$ & $0.34 \%$ \\
\hline Heilongjiang & -0.020 & 0.440 & 0.041 & 0.010 & 0.750 & 0.530 & 0.570 & 0.618 & $1.37 \%$ & $1.51 \%$ & $1.68 \%$ \\
\hline Shanghai & -0.045 & 0.467 & -0.313 & -0.540 & 0.317 & 0.721 & 0.803 & 0.905 & $2.02 \%$ & $2.27 \%$ & $2.54 \%$ \\
\hline Jiangsu & -0.033 & 0.413 & -0.052 & -0.079 & 0.257 & 0.594 & 0.647 & 0.703 & $1.84 \%$ & $1.78 \%$ & $1.73 \%$ \\
\hline Zhejiang & -0.010 & 0.435 & -0.113 & -0.160 & 0.501 & 0.583 & 0.607 & 0.628 & $1.11 \%$ & $0.84 \%$ & $0.68 \%$ \\
\hline Anhui & -0.016 & 0.428 & 0.438 & 0.996 & 0.951 & 0.536 & 0.579 & 0.627 & $1.44 \%$ & $1.61 \%$ & $1.63 \%$ \\
\hline Fujian & -0.023 & 0.428 & 0.329 & 0.734 & 0.802 & 0.539 & 0.587 & 0.656 & $0.93 \%$ & $1.78 \%$ & $2.35 \%$ \\
\hline Jiangxi & -0.019 & 0.434 & -0.342 & -0.780 & 0.504 & 0.525 & 0.556 & 0.591 & $1.13 \%$ & $1.18 \%$ & $1.26 \%$ \\
\hline Shandong & -0.011 & 0.422 & -0.438 & -0.696 & 0.833 & 0.533 & 0.558 & 0.584 & $0.94 \%$ & $0.94 \%$ & $0.93 \%$ \\
\hline Henan & -0.032 & 0.411 & 0.163 & 0.348 & 0.585 & 0.492 & 0.536 & 0.606 & $1.08 \%$ & $1.81 \%$ & $2.59 \%$ \\
\hline Hubei & -0.061 & 0.362 & -0.284 & -0.620 & 0.148 & 0.547 & 0.602 & 0.677 & $1.66 \%$ & $2.01 \%$ & $2.49 \%$ \\
\hline Hunan & -0.018 & 0.427 & 0.335 & 0.753 & 0.875 & 0.515 & 0.558 & 0.608 & $1.11 \%$ & $1.67 \%$ & $1.79 \%$ \\
\hline Guangdong & -0.032 & 0.427 & 0.455 & 1.000 & 0.788 & 0.591 & 0.691 & 0.811 & $2.69 \%$ & $3.38 \%$ & $3.47 \%$ \\
\hline Guangxi & -0.042 & 0.406 & -0.028 & -0.046 & 0.054 & 0.496 & 0.519 & 0.543 & $0.97 \%$ & $0.93 \%$ & $0.92 \%$ \\
\hline Hainan & -0.020 & 0.252 & -0.073 & -0.135 & 0.016 & 0.511 & 0.518 & 0.524 & $0.44 \%$ & $0.27 \%$ & $0.23 \%$ \\
\hline Chongqing & -0.039 & 0.283 & -0.267 & -0.536 & 0.052 & 0.501 & 0.508 & 0.516 & $0.28 \%$ & $0.28 \%$ & $0.31 \%$ \\
\hline Sichuan & -0.015 & 0.425 & -0.325 & -0.684 & 0.389 & 0.504 & 0.521 & 0.538 & $0.61 \%$ & $0.67 \%$ & $0.65 \%$ \\
\hline Guizhou & -0.035 & 0.405 & -0.109 & -0.276 & 0.313 & 0.508 & 0.551 & 0.604 & $1.53 \%$ & $1.69 \%$ & $1.92 \%$ \\
\hline Yunnan & -0.031 & 0.419 & -0.261 & -0.612 & 0.243 & 0.499 & 0.529 & 0.564 & $1.10 \%$ & $1.20 \%$ & $1.32 \%$ \\
\hline Tibet & -0.023 & 0.340 & -0.360 & -0.689 & 0.220 & 0.519 & 0.533 & 0.548 & $0.51 \%$ & $0.53 \%$ & $0.57 \%$ \\
\hline Shaanxi & -0.010 & 0.416 & -0.032 & -0.034 & 0.674 & 0.514 & 0.544 & 0.574 & $1.15 \%$ & $1.17 \%$ & $1.10 \%$ \\
\hline Gansu & -0.022 & 0.433 & -0.441 & -0.969 & 0.336 & 0.517 & 0.542 & 0.570 & $0.93 \%$ & $0.97 \%$ & $1.03 \%$ \\
\hline
\end{tabular}




$\begin{array}{cccccccccccc}\text { Qinghai } & -0.014 & 0.442 & -0.252 & -0.509 & 0.518 & 0.532 & 0.554 & 0.577 & 0.82 \% & 0.82 \% & 0.84 \% \\ \text { Ningxia } & -0.010 & 0.414 & -0.983 & -0.356 & 0.991 & 0.514 & 0.540 & 0.566 & 0.94 \% & 1.01 \% & 0.96 \% \\ \text { Xinjiang } & -0.020 & 0.411 & 0.319 & 0.742 & 0.713 & 0.493 & 0.490 & 0.513 & 0.29 \% & -0.12 \% & 0.94 \%\end{array}$

\section{Conclusions and Discussion}

The changes of the regional agricultural sustainability and its heterogeneity during 2003 to 2030 are examined. The research can be very useful for ensuring policy coherence between different regions. Results show that:

(1) Agricultural sustainability in China will continue to improve, and SADI will increase from 0.441 in 2003 to 0.612 by 2030 . SADI in Eastern, Central and Western China will respectively increase from $0.455,0.435$, 0.431 in 2003 to $0.681,0.602$ and 0.556 by 2030 .

(2) The gap in SADI among Eastern, Central and Western China has further grown. The coefficients of variation of SADI in the eastern, central and western provinces will increase from $0.045,0.026$, and 0.024 in 2003 to $0.181,0.073$, and 0.047 by 2030 , while the range will increase from $0.068,0.034$ and 0.032 in 2003 to $0.381,0.134$ and 0.091 by 2030 .

(3) Agriculture in Western China shows a low-speed of unbalanced development, while that in Eastern China shows a high-speed unbalanced development. Agriculture in Central China shows a low-speed unbalanced development from 2003 to 2015, while that shows a high-speed balanced development after 2016.

(4) The agricultural ecology, economy and rural society have significant contributions to the regional heterogeneity of agricultural coordination degree, while the agricultural environment, ecology, economy and technology have significant contributions to regional heterogeneity in agricultural development degree. The agricultural environment, ecology, economy, technology and rural society have significant contributions to the regional heterogeneity of agricultural sustainability. In different province clusters, sustainable agriculture should make positive progress in all six areas at the same time.

(5) The best performing provinces do not necessarily have the highest performance in all three dimensions of sustainable development, on the contrary, the worst performing provinces do not necessarily have the lowest performance in all six dimensions. The greatest weaknesses in the central and western parts of China are evident in economic and technological sustainability. The greatest weaknesses in Eastern China are evident in social and environmental sustainability.

Relevant research is carried out by establishing time-series data, which provides a new perspective and method for the dynamic analysis of sustainable development of agriculture. This type of assessment can provide a guide for national and regional public managers in making location decisions aimed at prioritizing actual actions, including contents as follows: (1) coordinating interregional agricultural policies, (2) increasing agricultural investment in $R \& D$, (3) implementation of agricultural ecological compensation, (4) strengthening sustainable agricultural measures such as organic and integrated production, (5) provide green finance support for provinces with high ecological vulnerability (6) increasing investment in the improvement of rural services and infrastructure for provinces with high socio-economic vulnerability.

However, this paper is still in its infancy and has certain limitations. Although the measurement index system established in this paper comprehensively considers the indicators related to the measurement of agricultural sustainability, it cannot cover all indicators that affect the agricultural sustainability. Therefore, the index system is still restrictive to a certain extent. As a result, how to better improve the measurement index system and analyze the agricultural sustainability with a faster and more effective measurement method should be further studied.

\section{Acknowledgments}

This work was supported by the National Natural Science Foundation (No. 72063001), Social Science Foundation of Jiangxi province (No.19GL23).

\section{References}

1. United Nations World Commission on Environment and Development. Our Common Future (The Bruntland Report). Oxford: Oxford University Press, 1987.

2. Dahl A L. Achievements and gaps in indicators for sustainability. Ecological Indicators 2012; 17: 14-19.

3. Kaynak S, Altuntas S and Dereli T. Comparing the innovation performance of EU candidate countries: an entropy-based TOPSIS approach. Economic Research 2017; 30(1): 31-54.

4. Mili S, Martínez-Vega J. Accounting for regional heterogeneity of agricultural sustainability in Spain. Sustainability 2019; 11(2): 299-312.

5. Cui H, Zhao L and Xue Q. Systematic analysis of regional agricultural sustainable development based on dissipative structure theory. Chinese Journal of Systems Science 2005; 1: 60-65.

6. Eugenio F B, Carlos O R and Enrique C T. Green accounting and sustainability of the Peruvian metal mining sector. Resources Policy 2010; 35(3): 156-167.

7. $\mathrm{Li} \mathrm{J}, \mathrm{Li} \mathrm{T}$ and Liu H. Research on the evaluation model of a smart grid development level based on differentiation of development demand. Sustainability 2018; 10(11): 1-25.

8. Giangiacomo B. The human sustainable development index: New calculations and a first critical analysis. Ecological Indicators 2014; 37: $145-150$ 
9. Liang $\mathrm{X}$, Liu $\mathrm{C}$ and Li Z. Measurement of scenic spots sustainable capacity based on PCA-Entropy TOPSIS: A case study from 30 provinces, China. International Journal of Environmental Research and Public Health 2018; 15(1): 10-28.

10. Yue C. Entropy-Based Weights on decision makers in group decision-making setting with hybrid preference representations. Applied Soft Computing 2017; 60(11): 737-749.

11. Liu J, Liu C and Han W. Efficiently evaluating heavy metal urban soil pollution using an improved Entropy-Method-Based TOPSIS model. Archives of Environmental Contamination and Toxicology 2016; 71(3): 377-382.

12. Li Y, Li Y, Zhou Y, Shi Y and Zhu X. Investigation of a coupling model of coordination between urbanization and the environment. Journal of Environmental Management 2012; 98: 127-133.

13. Liu S., Guo T., Dang Y. Grey system theory and its application. Beijing: Science Press, 1999. 